\title{
Fishing agreements in the lower Amazon: for gain and restraint
}

\author{
O. T. ALMEIDA \\ UFPA/NAEA \& IPAM, Campus Universitário do Guamá, Belém, PA, Brazil
}

K. LORENZEN

Division of Biology, Imperial College London, Silwood Park, Ascot, UK

\author{
D. G. McGRATH \\ UFPA/NAEA \& IPAM, Campus Universitário do Guamá, Belém, PA, Brazil
}

\begin{abstract}
Co-management agreements, whereby community rules for the management of local floodplain lake fisheries are legalised and enforced by the government, have become common in the lower Amazon. Agreements are intended to limit exploitation, in particular by commercial boats, to raise stock abundance and fisheries productivity for the benefit of local subsistence-oriented fishers and for conservation. A spatially replicated observational study was carried out to evaluate the performance of fishing agreements in terms of perceived rule compliance and actual impacts on fishing activities, catch and catch per unit of effort (CPUE, a measure of fisheries productivity and proxy for stock abundance). Perceived rule compliance was high, and this was corroborated by observed changes in fishing practices. Catch per unit of effort was significantly higher (by $48 \%$ on average) in areas subject to fishing agreements than in control areas without. Most likely this effect was attributable to the effective exclusion of mobile commercial fishing boats. Household fishing effort and catch in local communities were not significantly affected by the agreements, although a tendency towards slightly higher catches at lower effort was noticeable. In conclusion, the co-management agreements have led to greater local control over resources and brought significant productivity and conservation benefits.
\end{abstract}

KEYWORDS: Amazon, co-management, fishing, floodplain lakes, productivity.

\section{Introduction}

Active management of local fisheries by resource users, through self-governing institutions (community management) or sharing of management responsibility between resource users and governments (co-management) is widely seen as a key to improving fisheries management and reducing overexploitation (Sen \& Nielsen 1996; Pomeroy \& Berkes 1997). Where conditions are conducive for the establishment and persistence of such institutions, they can be effective at addressing common pool resource issues such as free riding (Ostrom 1999). Community or co-management may also have resource conservation benefits where they lead to overall reduced exploitation levels or the establishment of harvest reserves (Abell, Allan \& Lehner 2007). However, conservation benefits need not be the primary reason for establishing community or co-management institutions and further incentives, as well as substantial ecological knowledge, may be required to achieve them (Ruttan 1998).

In the Brazilian Amazon, community initiatives to regulate the exploitation of local floodplain lake fisheries have a long history (de Castro 2002). The nature of these initiatives has evolved rapidly since the 1960s, when expansion of commercial fishing led to increasing conflicts between mobile commercial and

Correspondence: Oriana T. Almeida, IPAM, Av. Nazaré, 669, Belém, PA 66 035.170, Brazil (e-mail: oriana@ufpa.br) 
local subsistence-oriented fishers (McGrath, de Castro, Futemma, Amaral \& Calabria 1993; Almeida, Lorenzen \& McGrath 2003; Almeida, McGrath \& Ruffino 2001). Commercial fishers are mobile, using motorised boats to operate throughout an extended area of the Amazon river-floodplain system and supplying mainly urban markets and fish processing plants. Commercial fishers engage in fishing as their primary occupation and tend to be urban-based in the upper, but ruralbased in the lower Amazon (Almeida et al. 2003). Subsistence-oriented fishers on the other hand tend to fish locally and to consume the bulk of their catch within the household. They practice fishing as part of a diversified semi-subsistence livelihood (McGrath et al. 1993; Smith, Nguyen Khoa \& Lorenzen 2005). Faced with increasing use of local resources by mobile commercial fishers, subsistence-oriented fishers have sought to establish and enforce local fishing restrictions aimed primarily at excluding commercial fishers. After initial, sometimes violent conflicts, intervention by government and NGOs has led to the establishment of a widely accepted co-management system. Federal fisheries law now allows communities to make local fishing rules, to complement the more widely applicable federal and state rules. Local rules may be registered with the government in the form of a fishing agreement, which makes them legally binding. The law does, however, enshrine the principle of open access to all fisheries resources, i.e. local fishing rules must apply equally to all fishers and cannot explicitly discriminate against outsiders (de Castro \& McGrath 2003). Fishing agreements are now widespread in the lower Amazon, have proved institutionally robust and meet key social and political objectives. However, it is less clear whether the agreements meet resource conservation objectives (de Castro \& McGrath 2003; de Castro 2000). Among the factors that may limit their effectiveness in this regard are difficulties of setting appropriate exploitation limits and the migratory nature of fisheries resources, which may negate localised conservation efforts.

This study provides an evaluation of the fisheries productivity and conservation benefits of fishing agreements in the lower Amazon. At core of the study is a replicated, paired comparison of fishing activities, catch and catch per unit effort (CPUE, a measure of fisheries productivity and proxy for stock abundance) in communities with management agreements (treatment sites) and similar communities without agreements (control sites). This study design allows assessment of the effectiveness of fishing agreements regardless of local variation in environmental conditions and details of management rules that are present among replicates.

\section{Methodology}

\section{Study design}

The impact assessment was designed as a paired observational study (Eberhardt \& Thomas 1991), comparing household fishing effort and catch between communities with established and successful co-management agreements and communities without such agreements. A paired design was chosen to minimise environmental variation and maximise the statistical power of the comparisons. Nine communities with established, successful fishing agreements were selected from a list of registered agreements. Only communities where agreements were perceived to be successful by community leaders, the commercial fisher's union, the federal environmental agency (Instituto Brasileiro do Meio Ambiente E Dos Recurcos Naturais Renováveis, IBAMA), and NGOs alike were selected. For each such community with a fishing agreement (treatment site), a similar local community without a functioning agreement was selected as a control site. Controls were selected based on similarity in terms of geographical proximity, dominant land type (upland or floodplain), and the size of lakes in the vicinity of the community. The study was thus spatially replicated at the community (management area) level.

\section{Baseline information on communities and fishing agreements}

Initial interviews were carried out with community leaders to obtain baseline information on communities, including a list of households that was used as a basis for selecting interviewees for the subsequent household survey. Information on the motivation for setting up fishing agreements and the specific rules stipulated in them was also obtained from community leaders and by consulting the text of agreements.

\section{Household surveys}

Detailed interviews were carried out in 259 households in the 18 communities. The same households were surveyed during October to December 2000 (low water season) and again during July 2001 (high water season). The survey covered basic information on livelihoods (sources of income and ownership of assets such as land, boats and cattle land holdings) and knowledge of the fishing agreement and its main rules. Detailed information on fishing activities and catches was collected for a recall period of 1 week. Fishing data were recorded separately by fishing location 
(floodplain lake or main river) and by gear type. Only effort and catch relating to floodplain lakes were used in the subsequent analysis, because fishing agreements do not extend to the main river. All values were scaled up to annual figures. Household surveys based on recall of fishing activities and catches by respondents are widely used to quantify catch and effort in subsistence-oriented and recreational fisheries, where diffuse landings make the use of conventional catch assessment surveys all but impossible (Bayley \& Petrere 1989; SEAFDEC 2004). Recall of catches by fishers tends to be reasonably accurate as long as recall periods are short, i.e. days up to 1 week. A comparison of catch weights estimated by Amazonian fishers with subsequent direct measurement showed that fishers' estimates were within $10 \%$ of the true weight in $70 \%$ of cases, and within $20 \%$ in and $90 \%$ of cases (G. Moisés, personal communication).

\section{Data analysis}

As fisheries were exploited by multiple gear types, fishing effort was standardised across gear types to obtain a consistent measure of total effort. In the household survey, effort was measured as hours fished and recorded separately by gear type. Effort expended by different gear types was standardised in units of gillnet effort as follows (Gulland 1983). The fishing power $P_{g}$ of gear $g$ relative to standard gear $s$ was calculated as the average of the CPUE ratio for the two gear types over all $n$ communities (denoted by index $i$ ) where both gears were used:

$$
P_{g}=\frac{1}{n} \sum_{i=1}^{n} \frac{\mathrm{CPUE}_{g, i}}{\mathrm{CPUE}_{s, i}}
$$

The average household fishing effort $E_{\mathrm{i}}$ of all gears in community $i$ is then given by:

$$
E_{i}=\sum_{g} E_{g, i} P_{g}
$$

Where $E_{g, i}$ is the average household effort expended by gear $g$ in community $i$. Average CPUE was calculated as average household catch divided by average standardised household effort.

The main assessment of impacts of the fishing agreements was based on differences in average household fishing effort, catch and CPUE between paired communities with and without fishing agreements. For each variable, the mean value in control sites is given as a baseline, and the effect of fishing agreements is reported as the mean and $90 \%$ confidence interval of differences between the paired sites
(Table 2). In the paired design, the mean effect is not the same as the difference between the means in impacted and non-impacted sites, and the nonimpacted (baseline) means are given only as an aid to interpretation. Exploratory analyses showed that the paired differences in catch and effort were skewed and leptokurtic, hence a non-parametric bootstrap (Efron \& Tibshirani 1993) was used to generate confidence limits for effects.

\section{Results}

\section{Description of communities and livelihoods}

The selected communities ranged in size from 18 to 156 households, with a median of 67 (Table 1). Five of the paired sites were located in the floodplain, while four were located in upland areas, but all had ready access to the river-floodplain system for fishing.

The major sources of household income were fishing, farming, cattle ranching and governmental salaries or benefits. Most residents received income in cash or in kind from several sources. About $84 \%$ of households engaged in fishing, mostly for subsistence. Only 7\% of households owned a motorised fishing boat and engaged in fishing on a more commercial basis. On average, fishing accounted for about $31 \%$ of total household income (in cash and in kind). Some $66 \%$ of households engaged in small-scale agriculture, producing mostly beans, watermelon, manioc and corn in an area smaller than 0.5 ha. About $48 \%$ of households engaged in cattle ranching, with a typical herd size of 22-32 heads. Just over half of all households $(51 \%)$ received income from the government either as wages or as retirement pensions. Most households thus had diversified livelihoods of which fishing was a major, subsistence-oriented component. There were no significant differences in the frequency of different income sources, land area cultivated, or cattle herd size between communities with and without fisheries co-management agreements.

\section{Fishing agreements}

Most fishing agreements had been operational for two or more years at the time of study, but one (Costa do Marituba) was in its first year (Table 1). Agreements were at different stages in the legalisation process, with five being fully legalised and four pending. Legalised agreements were monitored by environmental agents; community members trained for this purpose by the environmental agency IBAMA. All communities with agreements bar one had regular or good monitoring 


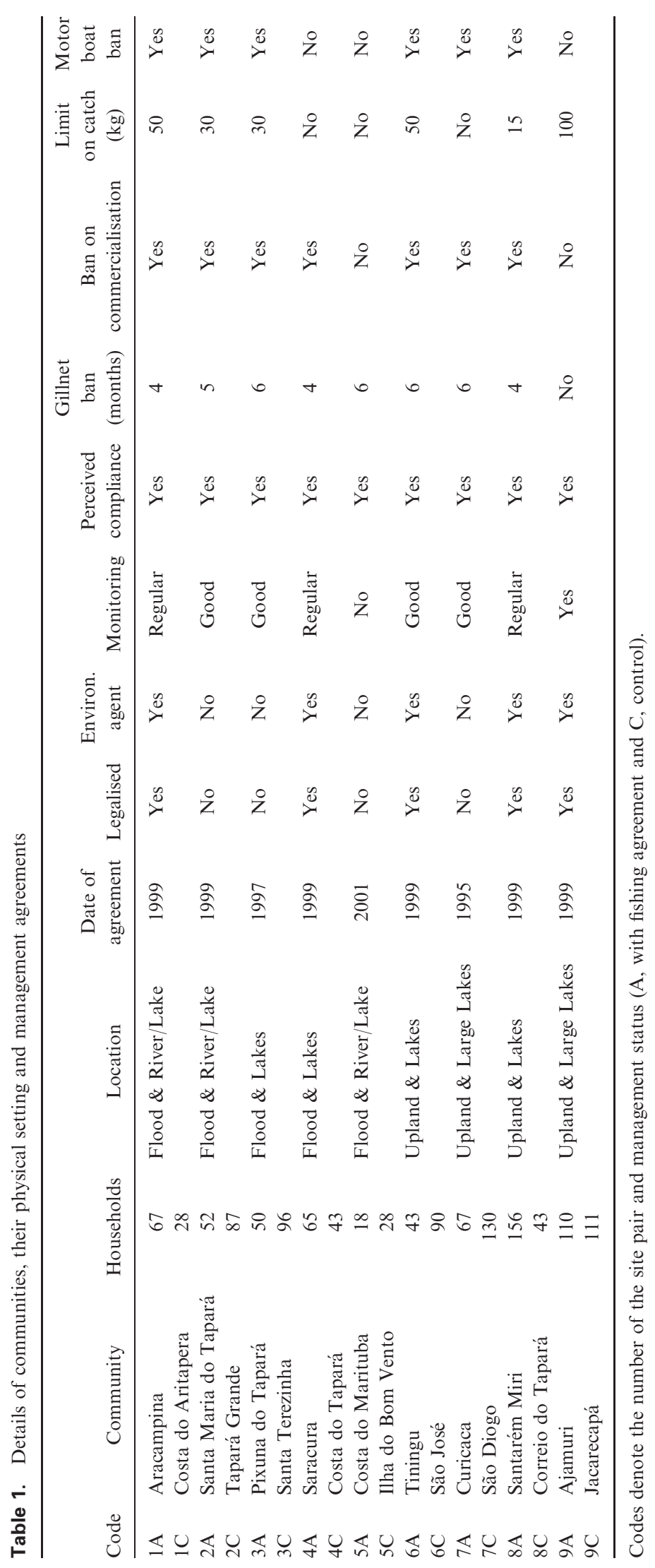

(C) 2009 The Authors. Journal compilation (c) 2009 Blackwell Publishing Ltd. 
arrangements. Within-community compliance with management rules was perceived to be good by the leaders of all communities. All agreements bar one stipulated bans on the use of gill nets for periods of 4-6 months during the low-water season. The majority (seven out of nine) of agreements explicitly banned commercialisation of catch, and six out of nine stipulated a daily catch limit of between 15 and $100 \mathrm{~kg} \mathrm{fisher}^{-1}$. The use of motorised boats was also banned in six out of nine agreements. All community leaders stated as the main reasons for establishing agreements the objective of safeguarding fish supply for the subsistence needs of the community while restricting commercial fishing, in particular by outside boats.

In the household survey, most respondents $(85 \%)$ correctly reported the main rules set out in the local agreement. Other details of the agreements, such as the year an agreement had been legalised were less commonly known (36\% of the respondents). The majority $(80 \%)$ of respondent in communities with fishing agreements considered the agreements successful. When asked about the proportion of community members complying with the rules, $70 \%$ stated that more than half the population complied.

\section{Impact of co-management on exploitation and fisheries productivity}

Total household fishing and catch in floodplain lakes were variable among communities and on average, not significantly different between those with and without fishing agreements (Fig. 1a, b; Table 2). A tendency for households in communities with management agreements to expend less fishing effort overall while obtaining slightly higher catches was noted, but was not statistically significant (Table 2). Standardised effort expended with gill nets was significantly lower in communities with fishing agreements than in those without. This was partially compensated by a (nonsignificant) increase in effort expended with other gears (Table 2). Catch per unit of effort was consistently and significantly higher, by $48 \%$ on average, in communities with fishing agreements than in those without. (Fig. 1c; Table 2).

\section{Discussion}

Fishing forms a key part of a diversified semi-subsistence livelihood for the majority of households in the lower Amazon floodplain. Safeguarding the resources upon which this local, subsistence-oriented fishery depends from commercial fishing, mostly by outsiders,
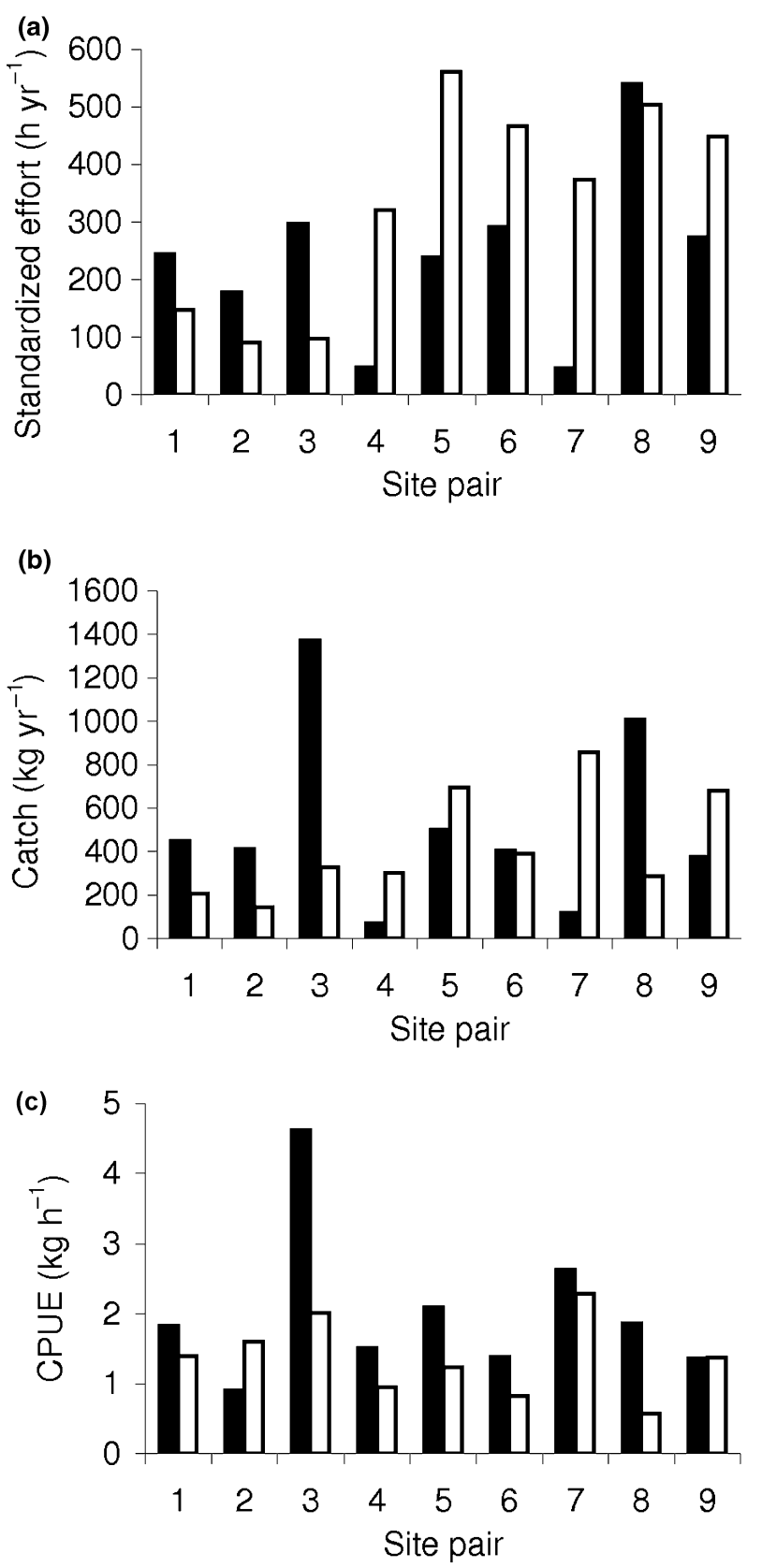

Figure 1. Comparison of standardised household fishing effort (a), household catch (b) and CPUE (c) in communities with (solid bars) and without (open bars) fishing agreements.

is the principal objective of communities in setting up fishing agreements. This objective is reflected in the nature of fishing rules such as bans on use of gill nets, motorised boat and daily catch limits which, while applying equally to all fishers, effectively eliminate commercial fishing while imposing only moderate restrictions on subsistence-oriented fishing. Compliance with management rules was perceived to be good 
Table 2. Effects of co-management agreements on average household fishing effort, catch and catch per unit of effort (CPUE) in floodplain lakes estimated from paired comparison

\begin{tabular}{|c|c|c|c|}
\hline Variable & Baseline (control) & Effect $[90 \% \mathrm{CI}]$ & Effect $(\%)[90 \% \mathrm{CI}]$ \\
\hline \multicolumn{4}{|c|}{ Standardised effort $\left(\mathrm{kg} \mathrm{yr}^{-1}\right)$} \\
\hline Total & 334 & $-95[-199,10]$ & $-28[-60,9]$ \\
\hline Gillnets & 247 & $-141[-225,-34]$ & $-57[-91,-14]$ \\
\hline Other gear & 88 & $46[-12,97]$ & $53[-14,110]$ \\
\hline Catch $\left(\mathrm{kg} \mathrm{yr}^{-1}\right)$ & 432 & $91[-163,333]$ & $21[-37,77]$ \\
\hline CPUE $\left(\mathrm{kg} \mathrm{h}^{-1}\right)$ & 1.36 & $0.66[0.20,1.03]$ & $48[14,76]$ \\
\hline
\end{tabular}

Mean values for control communities are given as a baseline, and effects are shown as the mean difference between paired communities with and without fishing agreements. Effects are also shown as a proportion of the baseline value. Effects in bold are significant at $P<0.1$.

by community leaders and members alike. This perception was corroborated by survey data, which indicated good knowledge of management rules in fishing households, and a significant reduction in household effort expended by gillnets compared with communities without fishing agreements.

Co-management agreements had a significant positive effect on fisheries CPUE, most likely reflecting an underlying, proportional increase in resource abundance. This positive effect of fishing agreements probably results primarily from the exclusion of outside commercial fishers. Exclusion of outside fishers reduces overall fishing pressure and also ensures that the full fisheries production is captured by the local community rather than shared with outsiders. Households catches were similar and standardised household effort slightly (but not significantly) lower in communities with management agreements than in those without. As fishing is a subsistence-oriented activity for most households, household catch levels reflect consumption requirements and fishing effort may be reduced when productivity (CPUE) increases. Benefits thus accrued to households primarily in the form of reduced effort to meet subsistence requirements, rather than increased consumption.

By raising resource abundance in floodplain lakes, the fishing agreements have conservation benefits. Floodplain lakes are key habitats for many exploited fish species (Martelo, Lorenzen, Crossa \& McGrath in press). The increase in community biomass (as indicated by CPUE) of $48 \%$ (with a $90 \%$ CI from 12 to $78 \%$ ) is in the same order as the $28 \%$ increase found in a meta-analysis of whole community biomass effects of marine reserves (Cote, Mosqueira \& Reynolds 2001). Much higher, up to threefold increases in community biomass were observed in some cases, including floodplain lakes in the Mekong subject to stringent access restrictions (Lorenzen, Garaway, Chamsingh \& Warren 1998). Analysis of aggregated catch-effort relationships for multispecies lake fisheries suggest that CPUE responses to effort variation are often moderate unless effort is reduced to very low levels (Lorenzen, Almeida, Arthur, Garaway \& Nguyen Khoa 2006).

This study provides the first rigorous evaluation of the productivity and conservation benefits of fishing agreements in the Brazilian Amazon. Nevertheless, the observational study design used here is more susceptible to biases than experimental studies where treatments are allocated randomly to experimental units (Eberhardt \& Thomas 1991). In this case, results could be biased if decisions to establish fishing agreements were influenced by the innate biological productivity of candidate lakes, or the pre-agreement level of commercial fishing within them. While this possibility cannot be conclusively rejected, great care was taken to select controls that were similar to the communities with agreements in terms of physical environment and accessibility to commercial fishers. No indication was found during interviews with community leaders that the decision to establish agreements was influenced by special or unique features of the lake under consideration.

In conclusion, co-management agreements resulted in productivity and conservation benefits, achieved primarily by excluding outside commercial fishers from the managed lakes. Exclusion of outside commercial fishers was also the most frequently cited reason for entering into co-management agreements in the first place. Community members co-operate to set up and implement agreements primarily for gain, but in doing so also show restraint by switching to less preferred gears and not increasing consumption (c.f. Ruttan 1998).

\section{Acknowledgments}

This research was supported by the Darwin Initiative, WWF, CNPq, and UK Department for International Development. Lucilene Silva, Luciene Campos Sales, 
Rosandra Santos, Leusabeth Silva, Kemerson Silva and Lucimar Lima helped with the data collection. Nalinda de Coutinho, Lucilene Silva, Tatiane Santos and Ivoneide Moreira entered data into the database and re-checked information in the field. Finally, the support of all community leaders, the Fishermen's Union, representatives of NGOs, and all the interviewees is gratefully acknowledged.

\section{References}

Abell R., Allan J.D. \& Lehner B. (2007) Unlocking the potential of protected areas for freshwaters. Biological Conservation 134, 48-63.

Almeida O., McGrath D.G. \& Ruffino M.L. (2001) The commercial fisheries of the lower Amazon: an economic analysis. Fisheries Management and Ecology 8, 253-269.

Almeida O., Lorenzen K. \& McGrath D.G. (2003) Commercial fishing in the Brazilian Amazon: regional differentiation of fleet characteristics and economic efficiency. Fisheries Management and Ecology 10, 109-115.

Bayley P.B. \& Petrere M. (1989) Amazon fisheries: assessment methods, current status and management options. Canadian Special Publication of Fisheries and Aquatic Sciences 106, 385-398.

de Castro F. (2000) Fishing Accords: The Political Ecology of Fishing Intensification in the Amazon. PhD Thesis, Bloomington, IN: University of Indiana, $206 \mathrm{pp}$.

de Castro F. (2002) From myths to rules: the evolution of local management in the Amazon floodplain. Environment and History 8, 197-216.

de Castro F. \& McGrath D.G. (2003) Moving toward sustainability in the local management of floodplain lake fisheries in the Brazilian Amazon. Human Organization 62, 123-133.

Cote I.M., Mosqueira I. \& Reynolds J.D. (2001) Effects of marine reserve characteristics on the protection of fish populations: a meta-analysis. Journal of Fish Biology 59(Suppl. A), 178-189.
Eberhardt L.L. \& Thomas J.M. (1991) Designing environmental field studies. Ecological Monographs 61, 53-73.

Efron B. \& Tibshirani R.J. (1993) An Introduction to the Bootstrap. London: Chapman \& Hall, 436 pp.

Gulland J.A. (1983) Fish Stock Assessment: A Manual of Basic Methods. Chichester: Wiley, 223 pp.

Lorenzen K., Garaway C.J., Chamsingh B. \& Warren T.J. (1998) Effects of access restrictions and stocking on small water body fisheries in Laos. Journal of Fish Biology 53(Suppl. 1), 345-357.

Lorenzen K., Almeida O., Arthur R., Garaway C. \& Nguyen Khoa S. (2006) Aggregated yield and fishing effort in multi-species fisheries: an empirical analysis. Canadian Journal of Fisheries and Aquatic Sciences 63, 1334-1343.

Ostrom E. (1999) Coping with tragedies of the commons. Annual Review of Political Science 2, 493-535.

Martelo J., Lorenzen K., Crossa M. \& McGrath D.G. (2008) Habitat associations of exploited fish species in the lower Amazon river-floodplain system. Freshwater Biology 52, 2455-2464.

McGrath D.G., de Castro F., Futemma C., Amaral B.D. \& Calabria J. (1993) Fisheries and evolution of resource management on the lower Amazon floodplain. Human Ecology 21, 167-195.

Pomeroy R.S. \& Berkes F. (1997) Two to tango: the role of government in fisheries co-management. Marine Policy 21, 465-480.

Ruttan L.M. (1998) Closing the commons: cooperation for gain or restraint? Human Ecology 26, 43-66.

SEAFDEC (2004) Handbook on Collecting Fishery Statistics for Inland and Coastal Fisheries. Bangkok: Southeast Asian Fisheries Development Center, 165 pp.

Sen S. \& Nielsen J.R. (1996) Fisheries co-management: a comparative analysis. Marine Policy 5, 405-418.

Smith L.E.D., Nguyen Khoa S. \& Lorenzen K. (2005) Livelihood functions of inland fisheries: policy implications in developing countries. Water Policy 7, 359-383. 